\title{
CORRUPCIÓN EN EL ÁMBITO INDUSTRIAL MILITAR. EL CASO DE ESPAÑA Y LA DIMENSIÓN INTERNACIONAL
}

\author{
Corruption in the Military Industry. \\ The case of Spain and the international dimension
}

Pere Ortega Grasa

Investigador y presidente del Centre Delàs d'Estudis per la Pau de Barcelona portega@centredelas.org

Cómo citar este artículo/Citation:

Pere ORTEGA GRASA (2018), “Corrupción en el ámbito industrial militar. El caso de España y la dimensión internacional", Hispania Nova, 16, págs. 712-734, DOI: https://doi.org/10.20318/hn.2018.4053
Copyright: (C) HISPANIA NOVA es una revista debidamente registrada, con ISSN 1138-7319 y Depósito Legal M 9472-1998. Los textos publicados en esta revista están -si no se indica lo contrario- bajo una licencia Reconocimiento-Sin obras derivadas 3.0 España de Creative Commons. Puede copiarlos, distribuirlos y comunicarlos públicamente siempre que cite su autor y la revista y la institución que los publica y no haga con ellos obras derivadas. La licencia completa se puede consultar en: http://creativecommons.org/licenses/by-nd/3.0/es/deed.es
Resumen: Los altos precios de los armamentos y el secretismo que rodea las exportaciones de armas, favorecen que este comercio este falto de transparencia, hecho que favorece prácticas corruptas. Los principales beneficiarios de la industria militar y de las ventas de armas es el denominado complejo militar industrial, un entramado donde se dan cita los intereses de los principales accionistas y directivos de las industrias militares, de algunos políticos y de altos mandos militares con el deseo de influir en las decisiones sobre política militar y la adquisición de armamentos de los Estados. España, no está exenta de esta problemática, pues la Ley que regula las exportaciones de armas permite que éstas sean tratadas como materia reservada.

Palabras clave: corrupción, complejo militar industrial, exportación de armas, transparencia, militarismo
Abstract: The high prices of armaments and the secrecy that surrounds the exportation of arms encourages a lack of transparency in this industry, given that it favours corrupt practices. The main beneficiary of the military industry and of the sales of arms is the so-called industrial military complex: a framework which brings together the interests of the main shareholders and directors of the industrial military, including some politicians and high military commanders who want to influence the decisions of military politics and of the acquisition of the armaments of the State. Spain is not exempt from this problem, as the Law that regulates the exportation of arms allows it to be treated as a classified matter.

Keywords: corruption, industrial military complex, exportation of arms, transparency, militarism. 


\section{Marco conceptual}

Una de las principales deficiencias de los Estados es la corrupción. Luchar contra ella debería ser una causa común de la comunidad internacional y sus principales organizaciones. Ante la gravedad de la situación, se creó Transparency International $(\mathrm{TI})^{1}$, una organización que todos los años publica un Informe donde indica un Índice de Percepción de Corrupción ${ }^{2}$, y que establece un ranquin de los países del mundo afectados por esta lacra. El trabajo de TI impulsó a Naciones Unidas a implicarse en la lucha contra la corrupción y a convocar, en 2004, una Convención contra la Corrupción ${ }^{3}$, en la que se articularon las medidas que los Estados deberían tomar para combatirla. En los informes surgidos de esta Convención, se señala que los sobornos sobre las políticas públicas de los gobiernos, el fraude corporativo, los carteles, la corrupción en las cadenas de suministro y en las transacciones internacionales -incluidas las financieras-, los desafíos relativos a los mercados de créditos de carbono y los fondos soberanos y de inversión juegan un papel determinante en la corrupción mundial.

Es en ese entramado multidimensional donde debe situarse la corrupción ligada al ámbito de la industria militar, que tiene una relación directa con conflictos armados y las causas que los provocan, entre las que se encuentran, sin duda, la producción y el comercio de armas. La misma TI estima que el coste global de la corrupción en el sector de defensa es como mínimo de veinte mil millones de dólares al año ${ }^{4}$. Ese mismo informe señala que solo el $10 \%$ de las empresas de armamento tienen información sobre sus propios sistemas internos de lucha contra la corrupción. Es decir, no existe

\footnotetext{
${ }^{1}$ Recuperado de https://www.transparency.org

${ }^{2}$ Recuperado de https://www.transparency.org/country/ Consulta (05/09/2017)

3 Recuperado de https://www.unodc.org/pdf/corruption/publications unodc convention-s.pdf Consulta (05/09/2017)

${ }^{4}$ Ibídem
} 
interés corporativo en las propias empresas de armamento, ni por parte de los estados donde se encuentran ubicadas, en controlar ni combatir la corrupción.

Un entramado en el que interviene el denominado complejo militar industrial, que conforma el conjunto de organizaciones y personas empresariales, políticos y altos mandos militares que rodean a los departamentos o ministerios de defensa, con el deseo de influir en las decisiones sobre política militar relacionadas con las adquisiciones de armamentos. Este entramado es el beneficiario directo de las decisiones adoptadas por los gobiernos sobre los presupuestos militares de los Estados, la industria de armas y su comercio; como también influyen en las decisiones sobre intervenciones militares o en las guerras fuera de sus fronteras; intervenciones que ineludiblemente conducirán al consumo de armamentos y a una mayor producción en las empresas.

El vocablo complejo militar industrial surgió del discurso de despedida de Dwight D. Eisenhower en 1961, como presidente de EEUU. Con este nuevo concepto denominaba al grupo de presión que, según él, mayor presión había ejercido sobre su política. Esta denominación ha hecho fortuna y se refiere al conjunto de organizaciones que rodean el militarismo entendido como la influencia de lo militar sobre lo político, es decir: las industrias de armas; los accionistas; las corporaciones financieras con fuertes intereses en ellas; los políticos que defienden esos intereses y que a su vez se encuentran vinculados a las industrias militares; los altos mandos de las fuerzas armadas, muchos de los cuales también tienen estrechos vínculos con las empresas de armas; las empresas de insumos y servicios que suministran a las fuerzas armadas; los sectores estratégicos como el de los hidrocarburos que son causa de militarización y guerras; y, finalmente, los organismos multilaterales militares donde también confluyen los intereses de todas las organizaciones anteriormente detalladas. Todos ellos son los beneficiarios directos de la inercia política que invade los países del mundo industrializado en favor de mantener un importante gasto militar para favorecer sus intereses particulares.

Un complejo militar industrial que tiene en el interior de las fuerzas armadas un aliado esencial, debido a que éstas se rigen por una estructura 
muy férrea. En general, las fuerzas armadas son un estamento muy corporativo, endogámico y encerrado en sí mismo, lo cual ayuda a que se oculten sus irregularidades y miserias. Un estamento donde todo se resuelve en el interior de sus dependencias e intenta que nada trascienda al exterior, y muy especialmente a los medios de comunicación, para evitar la crítica. Por otro lado, el estamento militar es muy patriarcal y jerárquico, el subalterno sólo puede obedecer y su opinión vale poco o nada ante la autoridad del mando superior. En el caso español, a diferencia de otros países democráticos, hay que añadir una cuestión muy preocupante. Las Fuerzas Armadas se rigen por un cuerpo jurídico militar propio, especial y separado de la jurisdicción civil, lo cual permite la parcialidad en las sentencias, al no ser los tribunales ordinarios los que enjuician los delitos. Eso impide que muchos casos de malos tratos, acoso, violencia de género o corrupción internos sean tratados de forma adecuada ${ }^{5}$.

\section{El complejo militar industrial en España}

En el Estado español también está presente un lobby militar industrial que ejerce esa presión sobre las decisiones de los políticos que gobiernan. Una buena prueba de ello es ver cómo las empresas militares se interesan por fichar como ejecutivos a políticos que han estado ligados al Ministerio de Defensa o a militares de alto rango de las fuerzas armadas. Esto es un hecho común en muchos países debido a los beneficios que obtendrán sus empresas de un personal con relaciones, conocimientos e información privilegiada sobre las políticas militares de los gobiernos. En ese sentido, España tampoco es diferente y en los últimos años se han prodigado los militares o políticos que, dejado el servicio activo, pasan a incorporarse como ejecutivos en empresas militares.

De entre estos personajes, el más llamativo es sin duda el anterior ministro de Defensa, Pedro Morenés, que ejerció como tal entre 2011 y 2016. Anteriormente, entre 1996 y 2000, con el gobierno del PP de José María Aznar,

\footnotetext{
5 Tomàs GISBERT, María de LLUC BAGUR i Gemma AMORÓS, La política militar del Gobierno Rajoy, Barcelona, Centre Delàs d'Estudis per la Pau, 2014. Recuperado de http://www.centredelas.org/images/stories/informes/informe22 cas.pdf Consulta (05/09/2017)
} 
Morenés ya había sido Secretario de Estado de Defensa, y entre 2000 y 2002, Secretario de Estado de Seguridad. Tras perder las elecciones se incorporó como ejecutivo o asesor en diversas empresas de seguridad y militares. Desde junio de 2010, había sido presidente de MBDA España. La empresa matriz MBDA está participada por tres de las principales industrias militares europeas (Airbus Group y BAE Systems en un $37,5 \%$ cada una y Finmeccanica/Leonardo en un $25 \%$ ) y se dedica a la fabricación de toda clase de misiles (en España el Meteor con un coste de $100 \mathrm{M} €$ ). Morenés también había sido consejero entre 2005 y 2007 de Instalaza, ubicada en Zaragoza y dedicada íntegramente a fabricar explosivos, en el pasado las minas antipersona y bombas de racimo (ambas hoy prohibidas en España), empresa a la que representó hasta 2011. Instalaza, en 2007, suministró bombas de dispersión a la Libia de Gadafi, justo antes de ser prohibidas en España. También había dirigido Segur Ibérica, la empresa de seguridad privada que realiza la protección armada de los barcos de pesca que faenan en el Índico frente a las costas de Somalia y Kenia. A su vez, había sido consejero de SAPA, empresa vasca dedicada íntegramente a la fabricación de armas pesadas y ligeras, así como explosivos y municiones.

Pedro Morenés, durante su mandato como ministro escogió a Pedro Argüelles como Secretario de Estado de Defensa. Argüelles, hasta su elección había presidido desde 2002 la filial estadounidense Boeing para España y Portugal y a su vez vicepresidente Boeing Internacional, empresa que ha suministrado a las fuerzas armadas españolas los aviones EF-18 Homet, Boeing 747, AV8V Harrier y los helicópteros Chinnok.

Otro caso de puertas giratorias entre el Ministerio de Defensa y las empresas militares es la designación, en junio de 2014, de Adolfo Menéndez al frente de la Asociación Española de Empresas Tecnológicas de Defensa, Aeronáutica y Espacio (TEDAE), la patronal que agrupa a la mayoría y más importantes empresas militares de España. Menéndez, es además miembro del Consejo de Administración de INDRA, empresa que suministra la mayoría de la electrónica que precisan los fabricantes de armas en España, simuladores de vuelo, dirección de misiles y de tiro de toda clase de armas. Precisamente Menéndez había acompañado a Pedro Morenés en el cargo de Subsecretario de Defensa cuando éste era Secretario de Defensa, durante el gobierno de 
José María Aznar. Fue precisamente Adolfo Menéndez quien vino a substituir al frente de TEDAE a quien fuera ministro de Defensa durante el gobierno del PSOE (1991-1995), Julián García Vargas, que estuvo al frente de esta patronal entre 2009 y 2013. Además, García Vargas había formado parte de la asociación USDAN, encargada de mediar en favor de los intereses de las industrias militares en exportaciones de armas frente a la Junta Interministerial de Material de Defensa y Doble Uso (JIMDDU), la Junta que aprueba o deniega las exportaciones. A su vez, fue vicepresidente de la Asociación Atlántica Española, una entidad civil de apoyo a la OTAN.

Al expresidente del Gobierno, José María Aznar, se le ha asociado a diversas operaciones de ventas de armas: en octubre de 2008, a la Libia de Gadafi, Argelia y Rusia a través de la empresa Einsa, en la que actuó como intermediario su amigo Miguel Blesa, cuando éste era presidente de Caja Madrid $^{6}$. También ex altos cargos del PSOE se han visto denunciados como participantes en las operaciones de ventas de buques a Venezuela por un importe de $1.700 \mathrm{M} €$. Ventas en las que intercedieron Javier Salas, ex presidente del Instituto Nacional de Industria (INI) hoy SEPI, hasta 1996, y Antonio Rodríguez Andía, subordinado de Salas en el $\mathrm{INI}^{7}$. Salas, una vez abandonado el INI, instaló un despacho de asesoría financiera, desde donde, según se desprende de una investigación llevada a cabo desde un juzgado de instrucción de Madrid, gestionó con Navantia la operación y ésta abonó 42 millones a varios comisionistas venezolanos y españoles, entre los que se encuentran Salas y Rodríguez. Ambos, acusados de tráfico de influencias, justificaron las comisiones como algo "normal" en este tipo de operaciones, algo que la misma empresa pública Navantia, del entonces INI, ratificó.

Eduardo Serra, tuvo una trayectoria de imparable ascenso dentro del Ministerio de Defensa, fue nombrado Subsecretario con la UCD en 1982. Posteriormente con la llegada del PSOE al gobierno, el entonces ministro Narcís Serra, lo mantuvo en su puesto y más adelante lo elevo Secretario de

\footnotetext{
${ }^{6}$ Cecilia GUZMÁN, "Aznar, de presidente del Gobierno, a comisionista en la venta de armas a Libia, Argelia y EEUU”, El Plural, 02/12/2013

${ }^{7}$ Carlos SÁNCHEZ, "Anticorrupción denuncia Javier Salas, último presidente del INI, por tráfico de influencias", El Confidencial, 04/04/2011
} 
Defensa. Finalmente el gobierno de José María Aznar lo nombró Ministro de Defensa. Tras dejar Defensa, se incorporó al consejo de administración de una docena de empresas. En la actualidad es presidente de Everis, una consultora y empresa de servicios aeronáuticos, que asesora en la adquisición de empresas a multinacionales (entre otros en el Consejo figuran, Álvaro Uribe y Ernesto Zedillo, ex presidentes de Colombia y México), que tiene como empresa asociada a Everis Aeroespacial y Defensa dedicada como su nombre indica al ámbito militar. Por último, Eduardo Serra es presidente de la Asociación Atlántica Española, una entidad surgida para dar cobertura a la OTAN.

Entre los altos mandos militares que han practicado la puerta giratoria de pasar del servicio activo en las fuerzas armadas a entrar como directivos en empresas militares destacan algunos casos. El más significativo por el cargo que ocupaba en la estructura militar fue el del almirante de la Armada Española Francisco Torrente Sánchez, quien, en junio 2006, ostentaba el cargo de Secretario General de Política de Defensa, un puesto considerado número dos en el Ministerio. Torrente Sánchez, pasó a la reserva y fue nombrado presidente de Expal, una industria fabricante de explosivos para las fuerzas armadas; y en 2009, elegido presidente de la patronal de empresas militares, Asociación Española de Fabricantes de Armamentos (AFARMADE), posteriormente disuelta para convertirse en TEDAE. Esta misma empresa Expal, escogió como administrador y consejero, también en 2006, al general Jesús del Olmo Pastor, quien fuera Director adjunto en el CESID, hoy CNI, los servicios de inteligencia españoles. Un Centro comandado por militares y donde un $60 \%$ del personal lo es. Jesús del Olmo, era conocido en los mentideros del Ministerio de Defensa como "Jesús del Gran Poder" por su rápido ascenso y poder dentro del Ministerio.

El general Carlos Villar Turrau, que fuera hasta julio de 2008 Jefe de Estado Mayor del Ejército de Tierra, fue contratado en febrero de 2009 como Vicepresidente de Estrategia de Negocios por General Dynamics/Santa Bárbara. Anteriormente, entre 2001 y 2006, fue Director General de Armamento y Material del Ministerio de Defensa, ocupándose, como el cargo indica, de la compra de armamento de Defensa. 
Otros casos similares, son el del Jefe de Estado Mayor de la Armada, el almirante Sebastián Zaragoza Soto, quien, tras su cese, tan sólo tres días más tarde se incorporaba, en noviembre de 2008, como asesor comercial para la exportación en la empresa pública Navantia. Otros militares han sido, Manuel García Berrio, Comandante en Jefe del Centro de operaciones aéreas, se incorporó como ejecutivo en INDRA. Carlos Gómez Arruche, Jefe del mando aéreo y José Manuel Gracia Sieiro, Director General del Instituto Nacional de Técnica Aeroespacial y antes Director General de Armamento, ambos entraron a formar parte de la plantilla de Airbus Group. Rafael Comas Abad, Jefe del Cuartel Terrestre de Alta Disponibilidad entró en la empresa de TRC de ingeniería militar. Juan Antonio del Castillo, Teniente General del Aire, que fue nombrado presidente de Hisdesat, empresa de comunicación por satélite donde operan todos los satélites militares del Ministerio de Defensa.

La incorporación de altos mandos militares a puestos de dirección de empresas de armamento, arroja dudas sobre la ética profesional de los militares, a quienes se les supone, como a todo funcionario público, cumplir principios de ejemplaridad, objetividad, honradez y confidencialidad. Principios que quedan en entredicho al incorporarse en empresas privadas que a su vez son contratistas del Ministerio de Defensa. Estas incorporaciones al sector privado son una clara vulneración de intereses que protege la Ley que regula a los Altos Cargos de la Administración del Estado.

Tampoco es que sean encomiables las actitudes de los políticos que abandonan el servicio público a la comunidad para ponerse al servicio de corporaciones privadas, donde, venderán sus conocimientos y conexiones políticas. Pero en cambio esto es un hecho frecuente, cuando vemos una gran parte de políticos se incorporan como asesores o ejecutivos en grandes corporaciones transnacionales.

Ambos casos, altos cargos políticos y militares, desde un punto de vista ético, son una deslealtad para con la ciudadanía y pueden considerarse como casos de corrupción, debido a la especificidad de la producción de esas empresas, material militar, que en el caso de ser exportado a países que violan la Ley de comercio de armas españolas y la Posición Común de la Unión 
Europea puede ser utilizado en conflictos armados y vulnerar los derechos humanos de poblaciones.

\section{Casos de corrupción en el Ministerio de Defensa de España}

En los medios de comunicación, periódicamente, aparecen informaciones sobre presuntos casos de corrupción en la contratación de servicios por parte del Ministerio de Defensa. Algunos de ellos actualmente en proceso de instrucción judicial. Diversos han sido los casos de corrupción descritos por el teniente Luis Gonzalo Segura en diferentes artículos y libros ${ }^{8}$, denuncias que han propiciado su expulsión del ejército.

Entre los últimos casos que han aparecido en los medios de comunicación se encuentra el de abril de $2015^{9}$, la imputación de trece contratistas de Defensa por cohecho, en la que estaban implicados dos tenientes coroneles que cobraban comisiones de esas trece empresas que operaban en áreas de seguridad privada, pólizas de seguros, alimentación y limpieza.

En otra ocasión ${ }^{10}$, el Ministerio de Defensa, paralizó la promoción de 22 tenientes coroneles del Cuerpo Militar de Intervención que habían sido clasificados para ascender a coroneles debido a un caso de presunta corrupción en la Inspección General de Sanidad, donde se detectó un delito contra la Hacienda militar en las contrataciones del hospital militar Gómez Ulla de Madrid.

Respecto a adquisiciones de armamento, la industria militar Instalaza ubicada en Zaragoza, pidió una indemnización de 40 millones de euros al Estado después de que el Gobierno firmará el Tratado de prohibición de las

\footnotetext{
${ }^{8}$ Luís GONZALO SEGURA, El libro negro del ejército español, Madrid, Akal, 2017.

${ }^{9}$ Miguel GONZÁLEZ, "Imputadas por cohecho 13 empresas contratistas de Defensa", El País, 14/09/2015.

${ }^{10}$ Miguel GONZÁLEZ, "Defensa frena el ascenso de 22 mandos por un caso de corrupción”, El País, 07/02/2016.
} 
bombas de racimo ${ }^{11}$, también conocidas como cluster, que esta empresa fabricaba. Indemnización que fue denegada por Defensa. Posteriormente, un informe sobre Instalaza ${ }^{12}$, realizado tras una pregunta formulada por el diputado Jon Iñarritu del grupo Amaiur en el Congreso de Diputados, sobre los contratos firmados por esta empresa con el Ministerio de Defensa, reveló, que se ocultó información de 23 contratos por un importe de 29,7 millones de euros, los cuales no fueron incluidos en la respuesta del Gobierno a éste diputado. Instalaza es una empresa de la que fue consejero y asesor Pedro Morenés entre 2007 y 2011, quién a partir de ese mismo año 2011, fue nombrado ministro de Defensa. Instalaza no recibió indemnización, pero sin duda fue compensada con un buen número de contratos.

\section{Corrupción en las ventas de armas españolas a Angola}

La empresa pública DEFEX, controlada por la Sociedad Española de Participaciones Industriales (SEPI), de la que posee el $51 \%$ de sus acciones, que tiene como actividad las exportaciones de armas producidas por industrias españolas de defensa. Esta empresa está siendo investigada por el juez José de la Mata de la Audiencia Nacional por una presunta trama de corrupción ligada a la exportación de armas a Angola.

Sobre este escándalo surgieron informaciones que relacionan a directivos de esta empresa con operaciones de exportaciones de armas, donde, al parecer, se incurrió en corrupción. Los imputados son, el expresidente de DEFEX, José Ignacio Encinas Charro, el director comercial, Manuel Iglesias Sarria, y el exdirectivo y coronel de las fuerzas armadas españolas Ángel María Larumbe, a quienes se imputa de cinco delitos: corrupción en transacciones comerciales internacionales, contra la Hacienda Pública, cohecho, blanqueo de capitales y pertenencia a organización criminal. DEFEX, estaba presidida por Juan Carlos Villamía, Teniente General del

\footnotetext{
${ }^{11}$ El Congreso de Diputados de España ratificó en marzo de 2008 el Tratado de Prohibición de las bombas de racimo.

12 Ximena VILLAGRÁN, "Defensa oculta compras por casi 30 millones a una empresa relacionada con Morenés", El Confidencial, 29/09/2015.
} 
Ejército, que había dejado el servicio activo en 2015 para incorporarse a esta empresa.

La dirección de DEFEX se sospecha que actuaba desde hace 20 años en operaciones de dudosa transparencia y se puede haber apropiado de decenas de millones de euros en comisiones ilegales, que se habrían repartido entre funcionarios de países compradores y los altos cargos mencionados. El caso de Angola sucedió en 2008, y consistió en la venta de material policial por valor de 152 millones de euros, pero, al parecer, en realidad solo se envió material por valor de unos 50 millones de euros, repartiéndose los 102 millones restantes entre autoridades angoleñas y los directivos mencionados de la empresa DEFEX a través de un entramado de sociedades ubicadas en paraísos fiscales. Entramado que gestionó Beatriz García Paesa, desde paraísos fiscales quién, a su vez, aparece en los "papeles de Panamá" filtrados del despacho Mossak Fonseca, como poseedora de cuentas en paraísos fiscales. Beatriz Paesa es sobrina del que fuera espía del CESID, hoy CNI, Francisco Paesa, que intervino en el caso del exdirector de la Guardia Civil José Luís Roldán, a quien ayudó a huir de España y actuó como testaferro en operaciones de ventas de material de seguridad y militar (municiones, camiones militares y aviones de transporte) en la misma Angola entre los años 1991 y 1993, por un importe de 33 millones de euros, ventas en las que también intervino DEFEX como empresa exportadora.

Entre todos los países africanos, Angola, hoy, lidera la clasificación de países que más presupuesto dedican a mantener sus fuerzas armadas, en 2014, destinó según el SIPRI ${ }^{13}, 5.152$ millones de euros a gastos militar, más que Sudáfrica y Nigeria juntas, que son las dos grandes economías de África. Angola se sitúa en el octavo lugar del mundo en el ranquin con más gasto militar en proporción con su PIB. Así, Angola, es un país altamente militarizado donde el ejército juega un papel muy importante dentro la estructura del Estado, hecho que condiciona la política de su gobierno siempre dispuesto a intervenir en los conflictos del continente. Además, Angola, es un país

${ }^{13}$ Recuperado de https://www.sipri.org SIPRI Military Expenditure Database Data for all countries from 1988-2016 in constat 2015 USD. Consulta (24/07/2017). 
altamente corrupto, ocupa el lugar 156 en el ranquin de $\mathrm{TI}^{14}$. Un país donde no existe división de poderes, su presidente, José Eduardo dos Santos, del MPLA, hasta agosto de 2017, ostentó el poder, fecha en que se celebraron unas elecciones manipuladas y no reconocidas por la UE, en las que accedió a presidente el que fuera hasta entonces ministro de defensa, Joao Lourenço. Estos hechos comportan que Angola sea un gran comprador de armas en el exterior para mantener su ejército y policía bien equipados. Durante el período de guerra civil, a pesar de ser un país embargado por la ONU, las armas continuaron llegando a los dos bandos, si el MPLA las recibía del bloque soviético, de la URSS y países del Este de Europa, sobre todo de Ucrania, Moldavia, Bielorrusia y República Checa, debido a que su gobierno se autodenominaba socialista y estaba apoyado por la URSS. La opositora UNITA, las recibía de la ultraderechista Suráfrica del apartheid.

La trama DEFEX se sospecha que operó en Egipto, Arabia Saudita y Camerún, de la misma forma que en Angola, con exportaciones de armas por valor de varios millones de euros. En Egipto, en el verano de 2010, se exportó desde España por 30 millones de euros en equipos de seguridad y defensa. La operación consistió en que Egipto pagaba como si hubiera recibido todo el material, mientras que solo se le suministraba una pequeña parte del mismo. Las ganancias pudieron ascender entre el 200 y el 300 por ciento, que se repartían entre los funcionarios corruptos egipcios y los responsables del entramado en España.

El coronel Larumbe, ejecutivo de DEFEX, actuaba a través de sus influencias en el Ministerio de Defensa sobre la JIMDDU, la Comisión interministerial que autoriza las exportaciones de armas de España, para que no se obstaculizaran las exportaciones que, en el caso de Angola habían sido denegadas. Influencia que también podía ejercer el presidente de DEFEX, el teniente General Juan Carlos Villamía.

Las exportaciones de armas de España a Angola no deberían haber sido autorizadas pues incumplen gravemente cuando menos cuatro de las ocho

\footnotetext{
${ }^{14}$ Recuperado de

https://www.transparency.org/news/feature/corruption perceptions index 2016 (06/09/2017).

Consulta
} 
condiciones que dispone la Posición Común y la Ley española de comercio de armas: ser un país que sufría un conflicto interno; continuar con tensiones internas; violaciones graves de los derechos humanos de la población; ser un país altamente militarizado pues tiene un gasto militar superior a sus necesidades de desarrollo humano, en especial salud y educación.

España exporta todos los años armas a otros países africanos que se cuentan entre los más pobres del mundo. Además de Angola, España vende armamentos a Burkina Faso, Kenia, Guinea Ecuatorial, Ghana y Mauritania ${ }^{15}$, países que debido a su elevado grado de militarización, dedican más recursos a gasto militar que los dedicados a salud y educación (PNUD) ${ }^{16}$. Entonces, las investigaciones que rodean las posibles corrupciones relacionadas con las exportaciones de armas a Angola, también podrían haberse producido en el resto de países africanos en los que DEFEX ha intervenido. Países, donde no hace falta decir que el estado de derecho es muy débil o inexistente y donde existe una enorme corrupción interna. La falta de información y transparencia en las exportaciones de armas españolas evidencian y favorecen, como en el caso de Angola, los posibles casos de corrupción.

\section{Las exportaciones de armas españolas en Oriente Medio}

La Unión Europea (UE) tiene aprobada una Posición Común ${ }^{17}$ sobre el control de las exportaciones de tecnología y equipos militares que establece ocho condiciones por las que no se debe vender armas a países sancionados, inestables, en conflicto armado, que vulneren los derechos humanos, que no condenen el terrorismo o que tengan un bajo nivel de desarrollo humano. Esta

\footnotetext{
15 FONT, T. y MELERO, E. Exportaciones españolas de armamento 2006-2015, Barcelona, Centre Delàs d'Estudis per la Pau, 2016. Recuperado de http://www.centredelas.org/images/INFORMES i altres PDF/informe29 cast web.pdf Consulta (05/09/2017).

${ }^{16}$ Recuperado de http://hdr.undp.org/es Consulta (10/06/2017.)

${ }^{17}$ Posición Común 2008/944/PESC del Consejo por la que se definen las normas comunes que rigen el control de las exportaciones de tecnología y equipos militares.
} 
Posición Común de obligado cumplimiento para los países miembros de la UE, en España se tradujo en una Ley que regula el comercio de armas ${ }^{18}$.

El último Informe de Estadísticas españolas de exportaciones de material de defensa y de productos y tecnologías de doble uso del año 2016, elaborado por la Secretaría de Estado de Comercio ${ }^{19}$, muestra que España ha llegado a un récord histórico en esta materia. Así, se han exportado armas por valor de 4.052 millones de euros, cifra a la que nunca antes se había llegado. De estas exportaciones, las más llamativas son las destinadas a los países de Oriente Medio, por ser susceptibles de ser utilizadas en los conflictos armados de la región. Los compradores más destacados fueron Egipto (219,29 M€), Omán (208,28 M€), Arabia Saudita (116,19 M€), Iraq (52,69 M€), Emiratos Árabes Unidos $(26,74 \mathrm{M} €)$ y Bahréin $(19,08 \mathrm{M} €)$. Además se debe incluir Turquía, que en 2016, recibió armas de España por valor de 167,9 M€. Un país europeo, pero en cambio fronterizo con Siria e implicado en esa guerra combatiendo a los kurdos y ayudando a los rebeldes que combaten al gobierno de Al Asad. En la Tabla 1 adjunta se muestran las ventas de armas españolas durante los últimos diez años, 2007-2016, y las cifras alcanzan el importe de 4.148 millones de euros y muestran como Oriente Medio es un mercado importante para las industrias de armas españolas. En la Tabla 1, Arabia Saudí, encabeza el ranquin de países que más armas ha adquirido en España, más del doble que sus inmediatos seguidores Emiratos Árabes Unidos, Egipto y Turquía, países que al igual que Irak, Bahréin, Israel y Catar están inmersos en los conflictos de la región.

\footnotetext{
18 Ley 53/2007, de 28 de diciembre sobre el control del comercio exterior de material de defensa y de doble uso, BOE, $n^{\circ} 312$, de 29/12/2007.

${ }^{19}$ Ministerio de Economía, Industria Competitividad. Secretaria de Comercio. Estadísticas españolas de exportación de material de defensa, de otro material y de productos y tecnologías de doble uso. Año 2016. Recuperado de http://www.comercio.gob.es/es-ES/comercioexterior/estadisticas-informes/PDF/INFORMEESTAD\%C3\%8DSTICAS2016.pdf .
} 
PERE ORTEGA GRASA

Corrupción en el ámbito industrial militar. El caso de España y la dimensión internacional

Tabla 1. Exportaciones Españolas de material de defensa a países del Oriente Medio y Turquía (en miles de euros corrientes)

\begin{tabular}{|c|c|c|c|c|c|c|c|c|c|c|c|}
\hline Países & 2007 & 2008 & 2009 & 2010 & 2011 & 2012 & 2013 & 2014 & 2015 & 2016 & $2007-2016$ \\
\hline Arabia Saudí & $1.876,66$ & & $5.148,35$ & $5.824,93$ & $14.006,43$ & $21.263,43$ & $406.437,36$ & $292.861,79$ & $545.979,75$ & $116.192,04$ & $1.409 .590,73$ \\
\hline $\begin{array}{l}\text { Emiratos Árabes } \\
\text { Unidos }\end{array}$ & 75,90 & 88,63 & 88,83 & & 66,15 & $2.379,60$ & $717.047,17$ & & $3.942,91$ & $26.738,86$ & $750.428,05$ \\
\hline Egipto & 385,59 & $1.316,38$ & 4,20 & $2.539,84$ & $69.834,52$ & $50.323,59$ & $126.653,09$ & $107.951,05$ & $106.412,58$ & $219.288,23$ & $684.709,06$ \\
\hline Omán & $1.267,68$ & 47,64 & 591,65 & $3.195,20$ & $3.310,39$ & 670,07 & $98.036,16$ & $64.893,48$ & $161.335,79$ & $208.281,73$ & $541.629,79$ \\
\hline Irak & & & & & & & & & $85.420,83$ & $52.690,81$ & $138.111,64$ \\
\hline Bahréin & $2.323,49$ & $15.945,28$ & & 40,69 & $6.350,52$ & $21.145,35$ & $24.129,99$ & $39.931,56$ & $3.238,88$ & $19.080,82$ & $132.186,58$ \\
\hline Jordania & 0,35 & 860,45 & 707,28 & $1.615,34$ & $2.584,94$ & 384,52 & 608,97 & 190,21 & $1.394,11$ & $5.096,95$ & $13.443,12$ \\
\hline Israel & $1.515,93$ & $2.358,99$ & 790,64 & $1.429,04$ & 472,55 & 637,84 & 52,13 & $3.428,09$ & $2.187,27$ & 530,93 & $13.403,40$ \\
\hline Catar & $1.187,72$ & $1.958,44$ & 835,65 & $1.030,48$ & 382,79 & & & 666,77 & 289,67 & 66,13 & $6.417,66$ \\
\hline Kuwait & & $1.155,22$ & & & & $1.703,01$ & & 817,80 & 834,00 & & $4.510,03$ \\
\hline Turquía & 0,63 & $1.113,19$ & $1.279,85$ & 357,00 & 66,35 & $31.629,00$ & $7.502,00$ & $243.673,00$ & $167.954,97$ & $85.000,00$ & $538.575,99$ \\
\hline Total & $8.633,95$ & $24.844,22$ & $9.446,45$ & $16.032,52$ & $97.074,64$ & $130.136,41$ & $1.380 .466,86$ & $754.413,75$ & $1.078 .990,76$ & $732.966,50$ & $4.233 .006,05$ \\
\hline
\end{tabular}

Fuente: Subdirección General de Comercio Exterior de Material de Defensa y de Doble Uso. Elaboración propia 
Aparte se deben contemplar las ventas de armas que llevan a cabo los principales exportadores de armas del mundo, por este orden, Estados Unidos, Rusia, China, Alemania, Francia y Reino Unido, todos ellos venden grandes cantidades de armamento en Oriente Medio, en especial Estados Unidos, que suministra armamento y ayuda militar a Israel, Arabia Saudí y a todas las petromonarquías de la región. Detrás de los seis mencionados se sitúa España que ocupa la séptima posición en ranquin mundial de vendedores de armas. Mientras que Rusia vende armas a los países rivales, Irán y Siria.

Las exportaciones realizadas por España y las de los países de la UE, pueden considerarse ilegales si se atiende a la propia legislación española y europea sobre comercio de armas debido a la situación de inestabilidad existente en la región de Oriente Medio, y en concreto, por la influencia regional de países como Arabia Saudí o Emiratos Árabes Unidos, en tanto que dan apoyo a una de las partes del conflicto en Siria, armando a los grupos insurgentes; como en otros países como Libia, o que forman parte de la coalición militar que está llevando a cabo una intervención armada en la guerra que se libra en Yemen. También las exportaciones españolas a Irak deberían estar prohibidas, en tanto que Irak está inmerso en un conflicto armado en su propio territorio combatiendo a Daesh y grupos sunitas rebeldes.

Es probable que todas estas armas exportadas a los países de Oriente Medio y Turquía estén siendo utilizadas en los bombardeos a ciudades kurdas, sirias, iraquís o yemenitas. Del mismo modo que la utilización de estas armas contribuya a la salida masiva de población que huye de la guerra hacia otros emplazamientos, incluida la actual crisis humanitaria de refugiados, algunos de los cuales pretenden llegar a Europa.

Sin embargo, el control de las exportaciones de armas no es un reto simplemente jurídico, no es suficiente comprobar hasta qué punto se ha cumplido o no la Ley que regula dichas exportaciones. El reto principal es ético y político por el desastre humanitario que produce. De alguna manera se puede afirmar que se pervierte la Ley, y en ese sentido, afirmar que estamos ante una corrupción de facto, pues si la Ley española es muy explícita en los casos en que no se deben exportar 
armas, y en cambio éstas llegan a países que violan la Ley, es que los mecanismos que regulan el estado de derecho están siendo corrompidos.

Para acabar con esta situación que permite que se viole la Ley, se debería acabar con la opacidad y el secretismo que rodean de las actas que elabora la JIMDDU. Junta que tiene como misión aprobar o denegar las exportaciones de armas, pues sus actas son declaradas confidenciales, es decir, "secreto de estado". Estas actas deberían ser públicas y estar a disposición de los grupos políticos del Congreso de Diputados. En estas actas se debería informar del tipo de armas que se exportan, y no sólo las categorías que las agrupa, y que en la actualidad sólo se informa en algunos casos, cuando el arma toma proporciones importantes, un avión o un buque de guerra. También se debería saber el nombre del fabricante exportador, que tampoco se enumera; como el nombre del comprador, si es un estado, un particular o una empresa, y no sólo, como ocurre ahora, el nombre del país comprador.

\section{Dimensión Internacional}

\subsection{BAE Systems en Arabia Saudí}

Es bien conocido que Arabia Saudí, es un país regido por una autocracia familiar, la familia Saud. Se estima que no son menos de medio millar los familiares que dirigen todo el entramado del Estado y ocupan la mayoría de puestos importantes de la administración saudí. A modo de ejemplo, el actual rey, Salman bin Abdelaziz, que heredó el trono de su hermano mayor, aún tiene 42 hermanos que por orden de edad le sucederán en el trono. Pero lo llamativo de esta plutocracia, no es la dictadura con que se rige y donde todos los resortes del estado, ejecutivo, legislativo y judicial están en manos del monarca, sino, que se trata de uno de los países más corruptos del mundo, así lo señalan todos los informes de Transparency Internacional, donde, en el último, ocupa el lugar 67 del ranquin de corrupción sobre un total de 176 países ${ }^{20}$. También es conocido que cualquier negocio que se quiera llevar a cabo en ese país debe ir acompañado de substanciosas comisiones para los miembros de la familia real

\footnotetext{
20 Recuperado de https://www.transparency.org/news/feature/corruption perceptions index 2016 Consulta (06/09/2017).
} 
que interceden en todas las negociaciones, y numerosas son las investigaciones y juicios por corrupción que han tenido lugar en diversos países.

Entre los múltiples casos de corrupción que rodean a la familia Saud, también se encuentran las adquisiciones de armamento, y el caso más escandaloso fue el que protagonizó la empresa británica BAE Systems, la principal industria militar europea y tercera mundial en ranquin de producción militar ${ }^{21}$. El 10 de abril de 2008, una sentencia del Tribunal Superior de Londres, dictaminó que era ilegal la decisión del Gobierno británico de cerrar una investigación sobre un acuerdo multimillonario de venta de armas entre el Reino Unido y Arabia Saudí. Los antecedentes de esa decisión se remontan a 2006, cuando la Oficina de Fraudes del Reino Unido (SFO), canceló, durante el mandato de Tony Blair como primer ministro, una investigación sobre un acuerdo de ventas de 100 aviones de combate por valor de 84.000 millones de dólares realizada en 1985.

Dicha investigación se originó por la denuncia presentada contra BAE Systems, a quién se acusaba de efectuar pagos ilegales a funcionarios sauditas para asegurarse contratos de armas. La cancelación fue ordenada por el propio Tony Blair, quien escribió una carta personal y secreta aduciendo como argumento que la investigación podía "perjudicar la seguridad británica" y añadiendo que se trataba de razones de "interés nacional". Las presiones del régimen saudita sobre Londres para frenar las investigaciones de soborno, fueron debidas a la implicación de varios miembros de la familia real saudita. En concreto el príncipe Bandar bin Sultán, quién fue uno de los receptores de las comisiones ilegales. Según la prensa británica, se trasladaron pagos secretos de entre 1.500 y 2.000 millones de dólares a dos cuentas bancarias en Washington pertenecientes a la embajada saudita, de donde bin Sultán sacó dinero para su uso personal ${ }^{22}$. Bandar bin Sultán viajó a Londres para ejercer personalmente presiones y se abandonara la investigación. Las presiones, consistieron en amenazar con suspender la colaboración de Arabia Saudí con el Reino Unido en materia antiterrorista, lo que podía permitir que ocurriera un nuevo atentando similar al de

\footnotetext{
${ }^{21}$ Recuperado de https://www.sipri.org SIPRI, Arms Industry Database Consulta (20/07/2017).

${ }^{22}$ Informe de la BBC News, Saudi prince received arms cash, 07/062007.
} 
Londres de 7 de julio de 2005. Objetivo que consiguió. Tras la suspensión de la investigación, Arabia Saudí acordó comprar al Reino Unido 72 cazabombarderos Eurofighter por valor de unos 8.700 millones de dólares. Afortunadamente, dos jueces del SFO ${ }^{23}$, dictaminaron que el Gobierno británico actuó de manera ilegal y dieron la razón a los dos grupos que realizaron la denuncia, a la Campaing Against Arms Trade $^{24}$ y Corner House Research ${ }^{25}$ de Reino Unido. Posteriormente, en febrero de 2010, BAE Systems, fue condenada al pago de una indemnización de 350 millones de dólares al Gobierno de Estados Unidos en concepto de dolo ${ }^{26}$.

\subsection{Finmeccanica / Leonardo y corrupción}

En febrero de 2010, India firmó un contrato para la compra de 12 helicópteros AW101 con la empresa italiana Agusta Westland, filial de Finmeccanica, por un importe de 560 millones de euros. Estos helicópteros estaban destinados al Escuadrón de Comunicaciones de la Fuerza Aérea de la India. La controversia sobre ese contrato salió a la luz en febrero de 2013, con la detención de Giuseppe Orsi, acusado de falsificar facturas y corromper a autoridades indias para conseguir el contrato. Orsi, era el director ejecutivo de Finmeccanica, la mayor empresa italiana de fabricación de armamentos, y líder europea en tecnología aeroespacial. En la actualidad, esta empresa se ha transformado en un holding industrial con representación en más de 100 países, en la que el Estado italiano posee el 30\% de las acciones de este holding. En el juicio celebrado en Milán que destapó los sobornos pagados, el tribunal condenó a Orsi a cuatro años y medio de cárcel y a otro ejecutivo, Bruno Spagnolini, de la filial Agusta Westland, a cuatro años de cárcel ${ }^{27}$. Además de ordenar a los dos ejecutivos

\footnotetext{
23 Recuperado de https://jenner.com/system/assets/assets/4715/original/Corner.pdf?1320256252 Consulta (06/09/2017)

${ }^{24}$ Recuperado de https://www.caat.org.uk/

${ }^{25}$ Recuperado de http://www.thecornerhouse.org.uk/

${ }^{26}$ Recuperado de

http://www.bbc.com/mundo/internacional/2010/02/100205 1852 multa sobornos bae If.shtml Consulta (05/09/2017)

${ }^{27}$ Recuperado de

http://www.prensa.com/mundo/Finmeccanica-hundida-escandalo-corrupcion 0 4214578668.html

Consulta (05/09/2017)
} 
que paguen 7,5 millones de euros por las sumas consideradas como sobornos. Finmeccanica, que cambió su nombre y hoy se denomina Leonardo, ha continuado suministrando material militar al gobierno indio.

La última semana de marzo de este año 2017, la prensa italiana se hacía eco de un nuevo caso de corrupción en Finmeccanica/Leonardo, y del arresto domiciliario de dos ex directivos, Lorenzo Borgogni, ex director de relaciones externas y Stefano Carli, ex director operativo de Selex Service Management, filial de Leonardo ${ }^{28}$. La empresa Selex Service Management, recibió 400 millones de euros en 2009, para diseñar y gestionar el sistema Sistri de seguimiento electrónico de rastreo de desechos especiales y peligrosos. Este sistema fue encargado por el gobierno italiano después de que la mafia napolitana, que controla la gestión de residuos de esa ciudad, diseminara los residuos contaminantes de forma incontrolada. El sistema Sistri nunca ha llegado a completarse ni a entregarse. Las investigaciones de la justicia napolitana en curso, centradas en el sistema Sistri, han puesto de manifiesto todo un sistema de facturas falsas y de sobre facturación entre Selex Service Management y otras sociedades, a través de las cuales se desviaban fondos a paraísos fiscales y a cuentas suizas, en algún caso, se ha observado que este dinero fue entregado en efectivo directamente en las oficinas de Finmeccanica. Dichos fondos estaban destinados al pago de sobornos y a la financiación de los partidos políticos italianos. Finalmente, Lorenzo Borgogni, tuvo que abandonar Finmeccanica en 2011, por las denuncias de soborno a funcionarios hindúes para asegurar la venta de los doce helicópteros AW101 antes señalados.

Algo similar ha ocurrido en Panamá, donde también se han vertido acusaciones de pago de sobornos a funcionarios panameños de un importe de 25 millones de euros por la venta de material de defensa valorado en 250 millones de dólares ${ }^{29}$. Algunos candidatos electorales panameños han planteado anular el contrato con Finmeccanica

\footnotetext{
28 "La India cancela el suministro de helicópteros tras un escándalo de corrupción", El Economista, $21 / 06 / 2017$

${ }^{29}$ Recuperado de http://www.prensa.com/mundo/Finmeccanica-hundida-escandalo-corrupcion 0 4214578668.html Consulta (05/09/2017)
} 
y sumarse a la investigación internacional de soborno y corrupción que se lleva a cabo en Italia contra esta empresa. 


\section{Bibliografía}

- María BAGUR, La incorporación de la mujer al ejército español, Informe no 31 , Barcelona, Centre Delàs d'Estudis per la Pau, 2016. Recuperado de http://www.centredelas.org/images/INFORMES i altres PDF/informe31 cas web.pdf

- Jordi CALVO y Alejandro POZO, coordinadores, Diccionario de la guerra, la paz y el desarme, Barcelona, Icaria, 2015.

- A. EINSTEIN, P. HOLDEN, B. PACE, Corruption and the arms trade: sins of comission, Sipri yearbook 2011, Solna (Suecia), Oxford University Press, 2011.

- Tica FONT y Eduardo MELERO, Exportaciones españolas de armamento 2006-2015, Informe $n^{\circ}$ 29, Barcelona, Centre Delàs d'Estudis per la Pau, 2016.

- Tica FONT, Eduardo MELERO, Camino SIMARRO, Exportaciones españolas de armamento 2005-2014, Barcelona, Centre Delàs d'Estudis per la Pau, 2015.

Recuperado de

http://www.centredelas.org/images/INFORMES i altres PDF/informe27 cas web.pdf

- GASTEIZKOAK, Colectivo, Estas guerras son muy nuestras. Industria militar vasca, Tafalla, Txalaparta, 2016

- Tomás GISBERT, María BAGUR, Gemma AMORÓS, La política militar del Gobierno Rajoy, Barcelona, Centre Delàs d'Estudis per la Pau, 2014 Recuperado de http://www.centredelas.org/images/stories/informes/informe22 cas.pdf

- Luís GONZALO SEGURA, El libro negro del ejército español, Madrid, Akal, 2017.

- Luís GONZALO SEGURA, Código Rojo, Barcelona, Destino, 2015.

- Luís GONZALO SEGURA, Un paso al frente, Madrid, Tropo editores, 2014.

- Nora MIRALLES, Género y cultura militar, Barcelona, Centre Delàs d'Estudis per la Pau, 2016. Recuperado de

http://www.centredelas.org/images/INFORMES i altres PDF/informe30 cat 16112016.pdf

- NACIONES UNIDAS, Oficina contra la Droga y el Delito. Convención de la Naciones Unidas contra la corrupción, Nueva York, 2004. Recuperado de 


\section{https://www.unodc.org/pdf/corruption/publications unodc convention-s.pdf}

- Bernardo NAVAZO, Un Ejército envuelto en papel burbuja, Madrid, revista Estudios de Política Exterior nº 156, Noviembre 2013.

- Pere ORTEGA y Xavier BOHIGAS, Fraude e improvisación en el gasto militar, Barcelona, Centre Delàs d'Estudis per la Pau, 2016. Recuperado de http://www.centredelas.org/images/informe26 cas web.pdf

- Pere ORTEGA, El lobby de la industria militar española, Barcelona, Icaria, 2015.

- Pere ORTEGA y Arcadi OLIVERES, El militarismo en España. Barcelona, Icaria, 2007.

- Pere ORTEGA y Arcadi OLIVERES, El ciclo armamentista español. Una panorámica crítica (1989-1999), Barcelona, Icaria, 2000.

-ROYAL COURT OF JUSTICE, London, 2008. Recuperado de https://jenner.com/system/assets/assets/4715/original/Corner.pdf?1320256252

- Javier María RUÍZ AREVALO, La corrupción como amenaza para la estabilización de postconflicto. Lecciones aprendidas en Afganistán, Boletín Electrónico 92/2015, Madrid, Instituto Español de Estudios Estratégicos.

- SIPRI yearbook 2016, Solna (Suecia), Oxford University Press, 2016.

- Frank SLIJPER, Guns, Debt and Corruption, Amsterdam, Transnational Institute, 2013.

- John F. TIERNEY, Warlord, Inc. Extortion and Corruption Along the U.S. Supply Chain in Afghanistan, Washington, Diane, 2010.

- UNIÓN EUROPEA, del Consejo por la que se definen las normas comunes que rigen el control de las exportaciones de tecnología y equipos militares, Posición Común 2008/944/PESC. 